\title{
Intenciones para una didáctica proyectual. Caso: asignatura Proyecto y Forma en la FAU-UNT
}

\section{Ben Altabef, Clara}

Resumen:

Con el fenómeno de la globalización y el quiebre cultural a partir de la revolución informática, aparecen fisuras y contradicciones significativas. Las transformaciones en el campo de la informática constituyen un punto de inflexión en el curso de la historia. Se ha producido ya una ruptura cultural en los sistemas de comunicación. La ilusión de la globalización como posibilidad de interacciones y comunicación confronta con una realidad tensada por asimetrías y exclusión de distinto orden. En el caso de la arquitectura, el escenario no es claro y, se visualiza una coexistencia de diferentes paradigmas e ideologías.

Si bien se han producido innegables transformaciones, creemos que la ruptura en términos de Khun, en cuanto al pensamiento disciplinar en su conjunto, aun es débil y borrosa. En este contexto, los contenidos teóricos disciplinares hay que considerarlos de naturaleza ideológico plausibles de transformación en vías de la construcción de un corpus objetivo y racional. Así los conocimientos teóricos acerca del proyecto y de la morfología deben estar en continua revisión dinámica, sistemática y critica. Se trata de constatar su aplicabilidad en relación a la realidad en que intervenimos.

Palabras claves: Enseñanza de la arquitectura - paradigma - ideología - teoría - practica.

$\left(^{*}\right)$ Dra. Arq. Facultad de Arquitectura y Urbanismo, Universidad Nacional de Tucumán. Profesora Asociada de Morfología III UNT. Investigadora CIUNT, categorizada II.

1. Proyecto, paradigma, ideología en arquitectura

Asistimos a un escenario de crisis cultural que deviene de las profundas transformaciones de la sociedad del siglo XXI que influye también en los campos profesionales y de enseñanza. Los cambios de paradigmas han 
producido también una crisis ideológica en lo disciplinar, lo que suscita búsquedas e indagaciones experimentales como así también la revalorización de algunos núcleos duros de la arquitectura.

Antonio Miranda considera entre varias interpretaciones que "Paradigma se entiende también como Arquetipo o Modelo o teoría o ideología dominante en un momento dado de la historia" (1999, p. 428). Desde esa perspectiva se puede asociar los términos de paradigma e ideologías encontrando puntos de contacto. Si bien en sentido estricto el termino paradigma surge en el campo de las ciencias, consideramos que también podemos extrapolar su uso y significado a otros ámbitos de conocimiento como es el campo de la arquitectura, entendiendo que si bien no pertenece al campo de la ciencia, ni el arte ni la tecnología1 de modo preciso sino que importa un campo disciplinar con entidad propia que llamamos de las disciplinas proyectuales. En el siglo XX hay una búsqueda y construcción de identidad y autonomía disciplinar. En la acepción de Battisti, también se podría llegar a homologar los términos ideología y paradigma en el sentido de que ambos reflejan un cuerpo de pensamientos, teorías y visiones significativos de un campo de conocimientos específicos de un determinado espacio y tiempo.

En este mundo occidental contemporáneo, presenciamos un momento de transición paradigmática y de múltiples ideologías, una etapa intensa de cambios de paradigmas en lo político, social y cultural. Esto significa repensar y replantear estructuras y conceptos vigentes durante mucho tiempo; lo que implica un tiempo de oportunidades, no ajeno de dificultades. Boaventura de Souza Santos (2010), pensador relevante del momento, señala "...Vivimos en tiempos de preguntas fuertes y respuestas débiles" (p. 7). Esto da cuenta que tenemos interrogantes profundos que dan lugar a diversos sondeos críticos y hasta contradictorios.

\subsection{La idea de paradigma y su relación con el campo de la arquitectura2}

Thomas Kuhn plantea dos modelos en torno a la evolución de la ciencia: el modelo acumulativo y el no acumulativo. El primero se basa en que:

....El desarrollo científico se convierte en el proceso gradual mediante el cual los conceptos han sido añadidos solos y en combinación, al caudal creciente de la técnica y de los conocimientos científicos, y la historia de la ciencia se convierte en una disciplina que relata y registra esos incrementos sucesivos y los obstáculos que han inhibido su acumulación. (Kuhn 1962, p. 23)

Es decir, la ciencia se convierte en una cronología acumulativa de sucesos y conocimientos. Por su parte, el modelo no acumulativo hace referencia a la corriente introducida por Karl Popper. La ciencia no se desarrolla por medio de la acumulación de descubrimientos, de hechos o creencias sino a partir de las confrontaciones de las creencias con las observaciones de los hechos, apareciendo la necesidad de reorganizar los esquemas mentales y formular nuevas creencias e hipótesis. Tal concepción proporciona, en el ámbito de la historia, una visión rupturista escasamente interesada por los datos cronológicos, lo cual le permite demostrar que, cuando los modos de explicar el mundo entran en crisis y colapsan, aparecen nuevos paradigmas científicos que se construyen no a partir de la acumulación de descubrimientos, de hechos o inventos, sino de procesos no lineales caracterizados por rupturas y cortes.

Según T. Kuhn, si bien el concepto de paradigma es ambiguo, puede ser aplicado de distintos modos y admite diferentes sentidos. Podemos decir que se trata de un conjunto de creencias e ideas que utilizamos para 
analizar y comprender el mundo, desde los cuales es posible investigar y generar conocimiento.

Para definir el concepto de paradigma en nuestro contexto de estudio, nos preguntamos ¿qué es un paradigma en el campo de la arquitectura? Sin embargo, primero habría que plantearnos si es factible establecer dicho paralelismo, ya que Kuhn define la idea de paradigma desde un punto estricto en las ciencias. Partimos de la idea de que la arquitectura no es una ciencia, sin embargo, dentro de su campo disciplinar hablamos y nos referimos permanentemente a paradigmas. También, al igual que en otros campos de la actividad científica, sólo en algunos momentos históricos ha prevalecido un único paradigma, entendido como un conjunto de creencias y como modelo hegemónico y de referencia. Por ejemplo, puede pensarse en el Beaux Arts y en los principios del Movimiento Moderno, que influyeron y prevalecieron en períodos prolongados.

Concebido el paradigma como una matriz disciplinar (p. 279), constituye el conjunto de realizaciones y conceptualizaciones universalmente conocidas que es asumido por la comunidad de cada disciplina, a la vez que se constituye en un patrón de investigación y de práctica posterior.

Cada matriz está conformada por:

1. Las "generalizaciones simbólicas" aluden a los "componentes formales o formalizables de una matriz disciplinaria". Pareciera que una ciencia es más poderosa cuando es mayor el número de generalizaciones simbólicas que tiene y están a disposición de quienes practican dicha ciencia. Khun plantea que toda revolución científica implica, entre otras cosas, "el abandono de ciertas generalizaciones, cuya fuerza, previamente, está dada por las definiciones o tautologías". (p. 280)

En arquitectura las categorías vitruvianas -firmitas, utilitas y venustas-, los llamados principios universales, componentes primeros de la arquitectura, configurarían precisamente las generalizaciones simbólicas a las que nos referimos. Debemos tener en cuenta que estos principios varían a través del tiempo de acuerdo con los distintos significados que cada una de éstas adoptan en un momento histórico-cultural determinado3 . Las categorías permanecen, lo que se modifica son los significados que se les puede atribuir a cada una de ellas. Esto implica una re-significación y actualización de las categorías mencionadas.

2. Las "partes metafísicas" (p. 282) de los paradigmas son los compromisos compartidos que se expresan en las creencias y que a través de modelos pueden establecer analogías y metáforas que ayudan a dar explicaciones, futuras soluciones a problemas y a plantear "enigmas no resueltos" o nuevos problemas. Si bien existen diversas explicaciones dadas por investigaciones de metodólogos que han tratado de elucidar el proceso proyectual en arquitectura, se podría afirmar que un ejemplo de enigmas diversos no resueltos son los procesos de producción de una forma como resultado de un proceso cognitivo.

3. Los valores están referidos a las predicciones, que pueden ser cuantitativas y cualitativas. En realidad lo importante es "que permitan juzgar teorías en la formulación y solución de los enigmas" (p. 283). En arquitectura el proyecto -como dispositivo e instrumento disciplinar- constituye una solución anticipatoria de un problema y podría constituirse en una predicción. Aunque los valores sean compartidos por los miembros de un grupo en una disciplina, su interpretación y aplicación puede variar de individuo a individuo incluso en una misma comunidad científica. Estas formas de aplicación de los valores son las que plantean los "problemas filosóficos acerca de la teoría del valor o la estética" (p. 285). Esto significa que aun dentro de los valores existen los 
valores especiales. Cuando se juzga, critica o evalúa y se produce, se lo hace con ciertos valores y depende de ellos el resultado.

4. Los ejemplares o modelos de soluciones a problemas planteados son los paradigmas, que ofician o funcionan como ejemplos "compartidos entre distintas comunidades" (p. 286). Se trata del conjunto de soluciones concretas a problemas teóricos y cuestiones técnicas. Podríamos considerarlos como ejemplos esenciales o primeros en el campo de cada disciplina.

En el campo de la arquitectura se pueden identificar ciertos modelos y procesos de producción de proyecto y de obras como así también los sistemas de representación usados como ejemplares que se aplican en determinado contexto socio histórico, a los paradigmas vigentes y su ideología. Obras de arquitectura significativa se comportan como paradigmáticas de ciertas ideologías, tales como la Ville Savoye de Corbu o el Pabellón de Mies son paradigmas del racionalismo, así como la Central de Yokohama de Zaera Polo representa un punto de inflexión en la arquitectura contemporánea.

Sin embargo, tanto en arquitectura como en otras disciplinas, no hay un solo paradigma, es decir, ni una sola teoría ni un solo sistema de creencias que dirige la disciplina, no se recurre a una sola estrategia teóricaexperimental, sino a una multiplicidad. “¿Cuándo se produce una revolución científica?” plantea Khun (p. 286). ¿Cuáles son los recursos, en términos de Kuhn, que fracasan y que producen la crisis de los paradigmas vigentes? ¿La inutilidad de esos recursos aproxima el advenimiento de un cambio, que llevará a una revolución? ¿Es posible hablar de una revolución en el campo de la arquitectura? La informática es motivo de cambios radicales. Extrapolando, y ante la complejidad sobre la cual tenemos que actuar, la arquitectura de partido, resulta insuficiente ya que nos conduce a una simplificación y reducción del problema y obstaculiza a veces el desarrollo de soluciones posibilitadoras.

El paradigma vigente ya desde el siglo XX se caracteriza por una crisis del determinismo, que implicaba ver el mundo como un encadenamiento de causas y efectos; una crisis de la objetividad y la simplicidad y el cuestionamiento de la razón. También todo esto lleva a controversias respecto del método y ha dado lugar a explicaciones aparentemente dicotómicas que, en realidad, podrían resultar complementarias.

Desde la perspectiva de la complejidad Denise Najmanovich (2008), señala acerca del conocimiento en general, que es preciso tener una visión integradora y que atienda a sus distintas dimensiones:

(...) Cuando salimos del mundo positivista, las cosas dejan de ser objetos puros del mundo (físico o lógico) para pasar a ser objetos de la experiencia, pero no de una experiencia lógica abstracta, sino de una experiencia humana, de interacción contextualizada, atravesada por nuestra peculiar corporalidad, nuestro lenguaje, nuestra cultura, nuestra emoción. (p.102)

En el paradigma moderno o de la racionalidad, también identificado como el paradigma de la simplicidad concibe el conocimiento como reflejo interno en el sujeto del mundo externo. El conocimiento pretende ser objetivo e independiente. Hay una ilusión totalizadora del universo, a través de un conocimiento puro logrado a través de un método científico, universal e infalible (Najmanovich, p. 50). El hombre habita un mundo mecánico, inodoro, incoloro e insípido, de modo se escinde el sujeto del objeto, es un sujeto a-histórico, abstracto. El saber es una mera visión virtual de ese mundo real. 
El paradigma posmoderno, contemporáneo también llamado de la complejidad caracterizado por la ausencia de verdades absolutas, no significa que estamos frente a un nuevo paradigma sino que hay un modo diferente de experimentar el mundo. No hay un solo método universal, previsible, infalible sino que hay un cambio global sobre el conocimiento. Hay debates sobre el determinismo frente al azar, la complejidad vs la simplicidad, el holismo y el reduccionismo. Aparecen nuevas teorías como la de las catástrofes y la del caos de R. Thom que tienen su incidencia en el mundo de la ciencia y de las artes como así también en la arquitectura. Las innovaciones científicas a través de la Teoría general de Sistemas, las investigaciones de Prigoyine en la termodinámica dan lugar a los procesos no lineales irreversibles que generan un nuevo orden de concepciones evolutivas dinámicas y estructuras disipativas de un orden fluctuante que abren una nueva mirada sobre el mundo y el universo, que también imponen una huella en la cultura arquitectónica. (Najmanovich, pp. 35-50)

Edgar Morin, a través de la Teoría del Pensamiento Complejo ha puesto en crisis profunda la epistemología contemporánea. Señala que necesario "sustituir el paradigma de disyunción/reducción/ unidimensionalización (...) por un paradigma de distinción/conjunción que permite distinguir sin desarticular, asociar sin identificar o reducir" (Morin 1990, p. 34); en otras palabras, es necesario reemplazar los principios de simplificación por los de complejidad, emanados del conjunto de nuevos conceptos, descubrimientos, de nuevas visiones y reflexiones que van a conectarse y reunirse.

Complementaria a esta visión, dentro de las líneas de pensamiento contemporáneo desde el sur, está la que desarrolla Boaventura de Souza Santos (2010), en lo que ha dado en llamar la ecología de saberes y la traducción intercultural, que comportan una iniciativa epistemológica que contrarresta lo que él llama pensamiento abismal, que no es otra cosa que la epistemología occidental, construida a partir de las necesidades de la dominación capitalista, producto del colonialismo político. Esta nueva mirada es una más de las construcciones contemporáneas que permitirían una nueva relación de equilibrio dinámico entre los principios de igualdad y el principio de reconocimiento de la diferencia (p. 8) en una línea de lo que se llama el pensamiento emancipatorio. Dentro de esta perspectiva cultural propone Descolonizar el saber, reinventando el poder, lo que podría entenderse como un marco de apertura a otro paradigma ideológicamente inclusivo de minorías que puede asemejarse a una postura un tanto utópica (p. 96).

Lo que caracteriza la nueva propuesta es la regulación social y la emancipación social. Esta última se basa en tres lógicas racionales: la racionalidad estética-expresiva de las artes y literatura, la racionalidad cognitivainstrumental de la ciencia y la tecnología, y la racionalidad moral-práctica de la ética y la ley del derecho (Santos, 1995, p. 2). Desde esta perspectiva el campo de las disciplinas proyectuales son medios también de emancipación.

El pensamiento posabismal puede así ser resumido como un aprendizaje desde el Sur a través de una epistemología del Sur. Esto confronta la mono cultura de la ciencia moderna con la ecología de saberes. Es una ecología porque está basado en el reconocimiento de la pluralidad de conocimientos heterogéneos (...) con relaciones continuas y dinámicas. La ecología de saberes se fundamenta en la idea de que el conocimiento es interconocimiento. (...). Para una ecología de saberes, el conocimiento-comointervención-en-la realidad es la medida de realismo, no el conocimientocomo-una representación-de-la-realidad. (p. 53)

En el campo de la arquitectura tampoco estaríamos en condiciones de definir situaciones únicas ejemplares, casi como sinónimo de paradigma en lo que se refiere tanto a la práctica profesional como a la enseñanza. Pero 
si bien no se puede tratar de establecer modelos ejemplares, buscaremos establecer tendencias y sus referentes conceptuales y operativos más adecuados al contexto donde practicamos y enseñamos arquitectura.

\subsection{Ideología y arquitectura: vigencia del enfoque de Emilio Battisti}

La relación de la arquitectura con la ideología ha sido abordada desde distintas perspectivas y se ha debatido entorno a ello en profundidad. En la acepción común, hay una aceptación de que ideología significa; sistema o conjunto de ideas y pensamientos de una persona o de una colectividad o de una época (RAE), o la ideología en su origen teórico como ciencias que estudia las ideas, su carácter, origen y las leyes que las rigen, así como las relaciones con los signos que las expresan. (Destutt de Tracy, Mémoire sur la faculté de penser, 1796), o como sinónimo de lo político, o como lo menciona Miranda homologando su sentido con el de paradigma como ya se ha señalado.

Como se ha señalado el tema de la ideología4 ha sido ampliamente tratado, y se nos hace necesario interpretarlo desde lo estrictamente disciplinar de la arquitectura a pesar de que podría ser considerado un tanto reduccionista, por lo cual resulta de interés conocer la perspectiva de un teórico de la arquitectura que ha abordado este tema y teniendo en cuenta su sesgo político y distancia temporal coincidimos en el espíritu de su posicionamiento en cuanto a la búsqueda de una construcción de conocimiento con rigor de lo especifico disciplinar. Emilio Battisti en su libro Arquitectura, Ideología y Ciencia, postula el rol político de la arquitectura en general y del proyecto como instrumento de acción en particular. Plantea que al tratarse la Arquitectura de una actividad que se caracteriza por una práctica empírica o técnica, debe tender a la construcción de una práctica científica sustentada en la elaboración de una estructura de conocimientos objetivos y racionales, en el marco del materialismo histórico y dialéctico e independiente de un estadio ideológico. Los fundamentos teóricos se basan en el concepto de práctica y contradicción. Practica en el sentido de Althusser, como "todo proceso de trasformación de una determinada materia prima, en un determinado producto, trasformación efectuada por determinado trabajo humano, haciendo usos de medios de producción (...) según características técnicas” ( $p$. 17). La contradicción hacia el interior de un determinado objeto de estudio o disciplina, implica redefinir los principios teóricos y prácticos de la misma (p. 58). Así la arquitectura y el proyecto se entienden como una práctica social que alberga en cada sub campo específico. Las nociones fundamentales entorno a los cuales se basa la ideología dominante del proyecto de arquitectura son tipología, tecnología y morfología, a los cuales corresponde conocimientos específicos (Battisti, 1975, p. 44). Atentos a la distancia histórica de esta teoría se reconocen estas categorías como invariantes epistemológicos disciplinares susceptibles significados varios.

La ideología en una práctica teórica como el proyecto de arquitectura, exige: confrontar constantemente los contenidos disciplinares en cuando a las contradicciones que presenta con el contexto político, la realización de ejercicios disciplinares insertos en un contexto general de prácticas sociales y de procesos de transformación puesto que inciden en la realidad en distintas escalas, cuestionar las metodologías mecanicistas, asumir los productos de conocimiento disciplinar como momentos de producción ideológico, y redefinir la base disciplinar de la práctica proyectual sobre la ciudad ámbito aplicación y contradicciones (p. 19).La tipología se entiende como un instrumento de conocimiento, de análisis y estrategia proyectual de producción, considerada un medio tradicional y hasta perimido mientras nosotros entendemos como factible de ser re significada y posible de operar por su enorme versatilidad. Nos interesa marcar y enfatizar el potencial de transformación y cuestionamiento que ofrece el proyecto de arquitectura. 
Existen ciertos prejuicios o supuestos erróneos acerca de la técnica. Uno de ellos es considerar que la técnica es neutral, es decir puede ser independiente de la cultura y de la política. En los distintos niveles que nos refiramos a la técnica, ésta no se involucra de modo imparcial e inocente. Las técnicas y tecnologías surgen de manifestaciones y necesidades de cada sociedad. Está implícita en la condición humana, y no se la puede separar de la cultura5 .

La selección y uso de los tipos de representación, de determinadas técnicas constructivas, significan tomas de decisiones de los arquitectos entre otros, como depositarios del poder intelectual y de ese modo son factores de poder y están al servicio de determinados sectores de la sociedad6 .

La dimensión morfológica de la arquitectura, o sea el estudio de la forma como categoría subsidiaria del proyecto es condición inherente a la concreción del proyecto y a la arquitectura. "Trata del estudio y conocimiento de la razón de la forma y constituye el todo material del proyecto" (Miranda, 1999). De tal modo que la forma es variable inescindible respecto del proyecto y de la arquitectura, en el sentido que vincula los modos de habitar con la materialidad técnica. (El uso y la construcción como condicionantes de la forma que es la dimensión especifica de la arquitectura).

En el conocimiento científico se observa la existencia de conocimiento objetivamente construido, cuestión que en ciertas áreas de la arquitectura esto no es evidente, por la tradición empírica que tiene como disciplina y por lo tanto ideologizado. El rol y papel del arquitecto dentro de un sistema capitalista es ocupar espacio dentro de la superestructura de modo de participar y construir un pensamiento dialéctico y crítico (Battisti, p. 224). La morfología, como parte de esa práctica empírica produce y reproduce conocimientos ideológicos y propone nuevos modos de organización de esos conocimientos que se expresa a través del proyecto entendido como instrumento de transformación y de conocimiento, en cuanto a representación de la materialidad de los procesos físicos.

Una primera contradicción en el área de la morfología es el origen histórico de la disciplina arquitectura por la cultura figurativa de la percepción en los factores de la representación y de la forma. Esta se vacía de contenido y se reduce a los efectos de representación. La segunda contradicción es el rol de los arquitectos, que como intelectuales, en el manejo de las representaciones, se convierten en sujetos funcionales a las clases dominantes actuando como ideólogos responsables de la estructura de poder (pp. 224-225). Esto más allá de todos los debates acerca de la autonomía disciplinar.

Este enfoque, reviste total vigencia y amerita una vigilancia epistemológica y una postura crítica, sobre todo en el rol de docentes arquitectos. Si pensamos en la intensa circulación de información por proceso de globalización, revolución informática, aparecen los discursos disciplinares contemporáneos surgidos en los países centrales, miradas eurocéntricas como únicos y hegemónicos, introduciéndose en nuestra realidad periférica latinoamericana con desajustes sustantivos. Por lo cual, sin tener una mirada ingenua ni de aislamiento con pretensiones de autosuficiencia, se impone un rigor crítico, que permitan interactuar acentuando lo propio pero en interrelación con lo ajeno.

\subsection{Distinciones entre Proyecto y Diseño}


Consideramos necesario señalar las diferencias entre proyecto y diseño para precisar la perspectiva en cuanto a la problemática. Esto permitirá explicar por qué hablamos de proyecto en la enseñanza de la arquitectura. A propósito acordamos en el concepto de arquitectura de Emilio Battisti (1975):

(...) La arquitectura, en el proceso de conocimientos que pretendemos adquirir y desarrollar, debe ser primordialmente un conjunto de prácticas que transforman y conforman un determinado ambiente físico, como modo de apropiación de la naturaleza por parte del hombre, en el particular caso de las relaciones de producción vigentes (y no, solo como forma de arte, o como pura expresión espacial de relaciones sociales, o bien como expresión técnica...) (p. 301)

La arquitectura como disciplina ideológicamente constituida merece analizarse con todos los factores que afecta, transforma y se desarrolla. En ese sentido, la arquitectura permite la trasformación, a través de un orden determinado del espacio del hombre como ser y del devenir de un colectivo en un medio cultural definido. Así, la arquitectura desde su origen ha permitido organizar la realidad física con orden material y cultural. ¿A qué nos referimos cuando hablamos de la noción de orden? Los cambios, y transformaciones, la diversidad cultural son referentes conceptuales en el hacer arquitectónico actual. Significa que para validar la práctica de la arquitectura y, por lo tanto, la generación formal contemporánea es necesario contemplar los parámetros sociales relativos a esa praxis.

El proyecto implica ante todo acción y "deseo de actuar" (Marina, 1993, p. 159). La ausencia del deseo impide desarrollar un proyecto. El proyecto, que se constituye como una anticipación involucra diferentes operaciones mentales: percepción, integración de información, toma de conciencia de un conflicto, juego de subjetividades, participación activa de la memoria. El proyecto se presenta como una estrategia del hacer, plantea objetivos (qué hacer), identifica y formula conflictivas y problemáticas, y está regido por la necesidad de generar ideas, su traducción formal mediatizada través de simbolizaciones representacionales.

En la idea del mundo como proyecto dinámico, el hombre es un ser que nada tiene de estático e inalterable, según el enfoque O. Aicher, está el concepto de cambio, implícita en el proyecto, en tanto obra de la creación del hombre, que comparte permanencia y transformación. En ese sentido afirma que el proceso de proyectar da lugar a una "descentralización de la verdad y la razón universal". El sujeto asume, a partir de su intuición y su razón, la construcción del proyecto. En este sentido, entendemos que en nuestra contemporaneidad sin verdades únicas estamos en un proceso de revisión continua, por lo tanto, se "carece de una única filosofía del proyectar y del hacer". Nos preguntamos entonces: ¿coexisten diversas filosofías, ideologías que expresan diferentes modos de proyectar? Dicho autor plantea la ausencia de un "reservorio de donde podamos extraer conocimiento objetivo" (Otl Aicher, 2001, p. 125, 134, 175). Se trata entonces de engrosar y objetivar con conocimientos específicos en lo disciplinar.

El proyecto de arquitectura aparece históricamente con la Modernidad como una formulación de una hipótesis de progreso, en el contexto de la arquitectura que se constituye como una práctica social, de un saber particular, culturalmente compleja. Una primera distinción es con el termino de composición, sobre el cual hay acuerdo de considerar como opuesto al de proyecto, por su origen en cuanto poner en posición y distribución diferentes elementos de modo armónico, de elementos existentes. Esto implica una noción opuesta a la idea de invención que conlleva la idea de proyecto en la modernidad. (Sarquis, 2003, p. 43, 156)7 . 
El diseño arquitectónico, como tal, tiene sus raíces en la producción industrial seriada, la que implica una fragmentación, apunta a las partes y proporciona una visión parcial, no por ello innecesaria. Munari (1981) define el diseño como el proyectar un objeto teniendo en cuenta los aspectos estéticos, el diseño así resuelve problemas al dar forma a objetos, de modo que se podría asimilar el significado de plan al de diseño. A pesar de las diferentes significados del termino diseño, se asocia con dibujar, formalizar bi o tridimensionalmente, en los años sesenta que se lo ha usado como sinónimo de proyecto. La idea de diseño remite a precisar la forma, se trata así de una actividad que se subordina al proyectar, constituyéndose esta última en una mucho más abarcadora que la primera. Tomamos la actividad de proyectar como una dimensión fundante en la enseñanza de arquitectura, puesto que comprende la generación de ideas (conceptos y configuraciones) al hacerlo, involucra la identificación de problemas y necesidades hasta la acción propositiva desde un punto de vista conceptual y también formal. Se plantea el proyecto como una dimensión que resulta inclusiva del diseño. La idea de diseñar implica precisar la forma, es la definición morfo espacial. Desde una perspectiva sistémica, el diseño correspondería a un subsistema del proyecto.

El proyecto es una dimensión epistemológica de la arquitectura y además es mediador y anticipación metodológica para la transformación de la realidad y creación de nuevas realidades a través de la arquitectura. Se constituye así en un dispositivo de orden técnico, artístico y cultural que tiene distintos campos de actuación; el campo de la formación, profesión e investigación (Sarquis J., 2004, p. 268, 274, 279). Hay un núcleo duro disciplinar sobre el cual es imprescindible estudiar, investigar para poder actuar.

De modo que consideramos el proyecto como una práctica social que con un fundamento conceptual e ideológico tiene un carácter cultural, permite desarrollar una acción propositiva en el orden conceptual y formal. A través de un lenguaje proyectual específico posibilita la prefiguración y la planificación transformadora del contexto social.

\subsection{Lenguaje y expresión en las disciplinas proyectuales. Innovación y tradición8}

Nos situamos en una posición no apocalíptica, ni nostálgica, sino más bien desde una integración. ¿Qué es lo que atraviesa las disciplinas proyectuales? El proyecto, que es elemento común en las disciplinas proyectuales presenta a la expresión gráfica como tema transversal, y común al quehacer académico y profesional.

Si proyectar es pensar para el futuro, surge seguidamente la aparente dicotomía entre innovación versus tradición, porque la idea de futuro incita a la de transformación. Entendemos la innovación como parte de cambios creativos que modifican las reglas y los materiales de cada campo disciplinar. Claramente la novedad alude solo cambios puntuales y efímeros mientras que la innovación implica permanencia y consolidación sostenida de ellos en el tiempo.

Cada disciplina tiene un pensamiento y por lo tanto un lenguaje propio que determina modos de expresión particulares. El proyectar y diseñar en arquitectura conllevan el desarrollo de un pensamiento y un lenguaje particular que denominamos lenguaje proyectual. El lenguaje es el límite y la expresión del pensamiento.

La complejidad en el pensamiento proyectual se deriva de la necesidad de conjugar distintas dimensiones que, en el lenguaje proyectual, se traducen en la morfología, en la tecnología, en lo funcional. Esta perspectiva permite señalar que el pensamiento proyectual es crítico e incluye al pensamiento lógico, el somático, el 
espacial, el lingüístico, el técnico manual y el trascendental (Breyer, 2004). El entrecruzamiento de diferentes tipos de pensamientos genera redes que, sin embargo, no se funden ni confunden, sino que dan lugar a una forma específica de pensar el proyecto. De tal modo, la elaboración de un proyecto arquitectónico implica una síntesis a partir de datos pertenecientes a múltiples disciplinas, como las ciencias humanas, las ciencias lógicoformales, el pensamiento filosófico, etc., que confluyen en la actividad de diseñar y se articulan entre sí.

Entre los fundamentos de la enseñanza del proyecto se identifica cuatro ideas centrales y significativas en la educación artística:

(...) la propia percepción como hecho cognitivo la relación de la intuición con el intelecto; la relación entre diferenciación y generalización y los medios (...) Los medios nos revelan sus características únicas por contraste con otros medios. Los medios no son algo secundario y según sea el medio también será distinto el mensaje que se quiere transmitir. (Arnheim 1993, p. 22, 17, 20, 29, 65)

El conocimiento y la manipulación de los diferentes materiales como herramienta de comunicación implican diferentes significados en su aplicación y como técnicas que son no están escindidas de la cultura a la cual pertenecen.

La arquitectura evidencia las huellas de los instrumentos y medios con que se la produjo. La selección y el uso de los instrumentos es una cuestión ideológica que tiene sus implicancias en los niveles de innovación en el plano conceptual e instrumental. No hay medios neutrales, sino que tienen intencionalidad.

\section{Geometría y arquitectura}

Las distintas geometrías tanto clásica como las no convencionales, han sido instrumentos de Interpretación y (decodificación) de la naturaleza. También como modos de ver, entender el mundo, pensar la realidad y hasta son metáforas de la realidad tal el caso del psicoanálisis con el nudo de Borromeo, como formas de registro de los mundos del hombre; y principalmente como gramática en el proyecto de arquitectura

En lo disciplinar específico la geometría es el instrumento primordial, producto intelectual, que permite interpretar el sistema de formas reales, esto es arquitectura como espacio construido. También como sistema grafico matemático, auto comunicación en los procesos proyectuales. Y como medio grafico para transmitir y para comunicar el proyecto antes, durante y después de la construcción. Esto es definir y delimitar la forma y el espacio. Cada una de las geometrías se enmarca en un Paradigma cultural predominante que les corresponde. No hare acá una reseña histórica y menos cronológica de las distintas geometrías, pero es preciso señalar que de acuerdo a cada paradigma epocal corresponde un paradigma disciplinar del cual resulta un lenguaje arquitectónico, mediatizado por determinadas geometrías y que han generado un tipo de espacio arquitectónico particular que representa y es símbolo e ideología de momento histórico. (Ver Figura 1)

Surge el interrogante ¿hay preferencias por alguna geometrías más que por otras?

Como señale hay tipos de arquitectura que usaron y usan geometrías racionales esto es (euclidianas) de figuras ideales e inmutables o Geometrías llamadas «sensibles» esto es no euclidianas, que valoran la posición y no la dimensión, la conectividad y las deformaciones (topología). En el ámbito de la generación formal arquitectónica, el uso de ciertas geometrías no euclidianas tales como la hiperbólica, elíptica, fractal y topológica tienen más 
posibilidades de implementación con los sistemas digitales. La complejidad en el desarrollo de las alternativas proyectuales como así también en su definición para su construcción, son más potentes desarrollados por los sistemas computacionales. La reducción a la cuestión geométrica-formal es habitual y deja de lado la complejidad de cuestión arquitectónica, por lo cual es preciso tener una mirada crítica sobre los resultados que podemos lograr. La descontextualización puede resultar fácil, por lo cual se requiere una mirada atenta y prudente en relación a su uso. No se debiera perder de vista cuestiones fundamentales que hacen a las condicionantes y apropiación de las formas a su contexto. Quizás en este mundo; lo digital aparece como revolucionario, pero si no la cargamos de contenido, y sentido, se puede tornar en vacío, frívolo y banal, como suele ocurrir en muchos casos.

¿Importa preguntarse cuáles son las influencias de lo digital y analógico o manual en el proyecto? Internet es uno de los más poderosos medios que ha transformado todos los campos de la cultura, la percepción y también la producción artística y por lo tanto los modos de pensamiento.

Desde el proyecto, las tecnologías digitales presentan varias aristas de análisis, desde su uso solo como medios grafico representacionales al inicio, hasta su implementación y evolución para generación formal y de arquitectura de investigación y experimental como el diseño paramétrico.

Los procesos, herramientas o medios digitales constituyen un repertorio bastante amplio de recursos y condiciones y la tecnología computacional implica una apropiación digital. La arquitectura, en sentido convencional es, en tanto forma construida, remite a la estabilidad y a lo material, frente a la idea de realidad virtual asociada al ciberespacio y al medio digital. Desde esa perspectiva cabe el interrogante: ¿existe la arquitectura virtual?, algunos opinan que solo es grafica digital, una posibilidad de ser y que no va a ser nunca. Pero desde lo experimental la realidad virtual existe y si existe como un modo de habitar el espacio; se podría afirmar que es posible una arquitectura virtual.

Peter Einsenman (2008), nos habla de las posibilidades en un mundo hipermediatizado:

¿Cuáles son las cuestiones a las que se enfrenta la arquitectura en la actualidad? En primer lugar, es un hecho que vivimos en la era de los medios de comunicación, sobre los cuales apenas tenemos control (...). Hoy en día es difícil ganar un concurso con el proyecto de un edificio recto: parece que los edificios deben hacer gimnasia, retorcerse, girar... Esta es la arquitectura de la era de los medios de comunicación. (...) Cualquier grupo de jóvenes arquitectos quiere ser vanguardista. Ninguno de mis estudiantes desea saber nada sobre Palladio ni sobre Le Corbusier. Lo que quieren es el último afrodisíaco arquitectónico (...) todos quieren saber cómo ser Zaha Hadid. (...) En la actualidad, a arquitectura está perdida en la cultura de lo espectacular, en la idea de imagen, de marca, en lo que sólo puede llamarse promoción (...) la arquitectura se ha convertido en superficie, y los efectos de la superficie nos intoxican. Hoy mis estudiantes no pueden dibujar plantas; dicen que ya no necesitan secciones, sino modelizaciones en tres dimensiones. (....) La famosa sentencia de León Battista Alberti según la cual una casa es una ciudad pequeña; y una ciudad, una casa grande, constituye la primera afirmación de la relación de la parte con el todo pero tras haber servido de sostén a la arquitectura durante quinientos años, esa relación se encuentra ahora en tela de juicio. Ahora los arquitectos creen que lo importante tiene que ver con los componentes y con la infinita reproducción de la variabilidad. La informática plantea estas dos cuestiones: la idea del componente y la idea de la superficie. (...) Predomina la concepción de las partes sobre el todo, coincidente con la cultura de la imagen (superficies) y la subestimación del todo, en el proyecto, ya 
que se puede acceder a los componentes y sus relaciones por medios digitales de modo casi instantáneo y simultáneo.

Uno de los riesgos de los medios digitales es que es sencillo visualizar las partes en 3D y se pierde la idea del todo y las relaciones de escala. Hay una seducción por el fragmento que enmascara reconocer la importancia de la totalidad en una obra de arquitectura. El todo, aun con sus distintas concepciones, sigue siendo primordial y más aún en el campo de la formación de los arquitectos. Hay un inter juego de escalas donde el todo y las partes deben estar presentes.

A su vez los medios analógicos posibilitan un tiempo más pausado que trasunta en un hacer donde hay un pensamiento más reflexivo, aunque sea con ritmo más lento: la mano que piensa como señala el finlandés Pallasma.

Si bien cabe señalar que hay excelente arquitectura de autor, el problema se suscita en el ámbito de la enseñanza y además en el cómo hacemos ciudad, para no caer en una banalización del proyecto.

El uso de la tecnología digital en el proyecto de arquitectura resulta controversial. (Piñón, 2006). Por un lado, la suerte de mitificación que ha realizado el comercio de estos nuevos instrumentos, por otro muchos profesionales conservan cierta resistencia en su uso, mientras que otros consideran banalmente que se trata solo de ahorro de tiempo y esfuerzo, en la medida que permiten la reproducción y repetición más eficientemente que el dibujo artesanal, o sea como facilitador en términos de representación. Y también están quienes fantasean con una mayor creatividad para producir formas y estructuras sorprendentes, actitud que no deja de ser frívola y superficial. A la vez afirma que:

(...) el uso de la computador en el proyecto de arquitectura propicia el ejercicio de la mirada y fomenta la capacidad de juicio, al facilitar la visualización previa de los extremos del objeto con diferentes niveles de precisión, a distintas escalas a la vez (...) Aunque parezca una paradoja, la pc exige mucho mas de quien proyecta, ya que le ofrece más variables sobre las que actúa el juicio, aumenta su responsabilidad en la calidad del resultado. (Piñón, 2006, p. 144)

Ciertas arquitecturas contemporáneas de valor, claramente implementan y complementan recursos diferentes. Esto se advierte en generaciones de jóvenes arquitectos, tanto de países centrales, no pertenecientes al star system y de Latinoamérica. En nuestro continente, la generación de jóvenes arquitectos (S. Benítez, A. Aravena, R. Iglesias, F. Uribe, Mazzanti) busca autenticidad en expresión de sus producciones, tanto de sus obras como en los discursos.

\section{Enseñanza e ideología}

“(...) Reformar el pensamiento para reformar la enseñanza y reformar la enseñanza para reformar el pensamiento" (Morin, E., 1999, p. 21)

Consideramos preciso partir de los siguientes supuestos generales acerca del proyecto:

- La arquitectura y el proyecto se consideran actividades esencialmente creativas, que implican capacidad de transformación. 
-El proyecto en arquitectura constituye, en el proceso de formación, el núcleo integrador de conocimientos.

-El proyecto, en tanto trayectoria flexible y abierta, posibilita un aprendizaje crítico y continuo.

-El proyecto puede actuar como eje central del dispositivo pedagógico multidimensional, esto es como texto y pre-texto en el acceso al conocimiento.

La enseñanza del proyecto de arquitectura, presenta una influencia directa de factores culturales, institucionales y sociales que exceden lo estrictamente disciplinar. Esto muestra la necesidad que la enseñanza del proyecto sea tratado desde distintos campos de estudio: el pedagógico y el arquitectónico. La reflexión sobre la integración de los aspectos teóricosprácticos propicia la construcción del tercer campo que es el de la didáctica proyectual. (Ver Figura 2)

Es preciso trabajar en el entrecruzamiento de saberes; conjugar la indagación de la lógica disciplinar con los aspectos didácticos-pedagógicos; y con una perspectiva crítica, identificar la relación recíproca entre teoríapráctica con una perspectiva crítica. Nos planteamos distintas hipótesis o supuestos principales en los distintos campos referenciales.

En cuanto al campo disciplinar arquitectónico, se tiene como hipótesis9 que a una determinada forma de producir y hacer arquitectura, corresponde un determinado modo de enseñanza de la disciplina. Se evidencia que la formación disciplinar y la práctica profesional siempre han estado ligadas. El estrecho vínculo de esta relación se expresa en los pares: producción del proyecto-ámbito profesional y reproducción del proyecto-ámbito de enseñanza. Si se modifican los modos de producir la arquitectura, necesariamente se modifican los modos de enseñarla.

Concepto y forma10 constituyen un par de ineludible análisis en el proyecto. Uno de los momentos críticos en el proceso de diseño se presenta en el paso del concepto a la concreción formal, de la idea conceptual a la formalización. Si se considera que el proceso de proyectar es recursivo (esto es, no lineal, donde uno y otro pueden ser causa y efecto), la forma puede también retroalimentar la misma generación de la idea, es decir, la formalización se convierte en fuente de producción de conceptos. Además, no constituye un solo momento sino diversos momentos que se dan a lo largo de la trayectoria del proyecto. Por lo cual tenemos como hipótesis que en el proyecto arquitectónico el tránsito del concepto a la forma se posibilita a través del uso de diferentes estrategias de enseñanza11.

En el campo disciplinar arquitectónico se tiene como supuesto que de las distintas lógicas de proyecto surgen diversas estrategias proyectuales. Estas serán desarrolladas en el siguiente apartado.

\subsection{La didáctica proyectual como eje ideológico de la enseñanza de arquitectura}

La didáctica es la disciplina teórica que se ocupa de las prácticas de la enseñanza y que tiene como misión describir, explicar y establecer normas para la acción de enseñar. (Camillone, 2007, p. 22)

Importan los aportes en los estudios metodológicos específicos disciplinares en los abordajes de esta temática, basados en paradigmas en la conceptualización del diseño o proyecto (Burgos, 2010). 
Herbert Simon con una visión positivista considera el diseño como una ciencia artificial basada en la organización, planificación y orientación de problemas; o el procesamiento y sistema de datos, entiende el diseño como resolución de problemas (problem solving). Entiende el diseño como una mezcla de conocimiento teórico y habilidades prácticas, para la formalización de artefactos, como actividad preeminentemente racional que tiene injerencia en el mundo de lo artificial como actividad netamente racional y sintética (2006, p. 5) a diferencia del conocimiento científico de carácter analítico de la ciencia.

La perspectiva constructivista de Donald Schonn entiende el diseño como construcción de problemas a partir del concepto de conocimiento en la acción, basado en la reflexión sobre la acción, que tiene que ver con las disciplinas que se aprenden haciendo12. Según el autor se presenta una paradoja y a la vez dilema: "el estudiante no comprende lo que necesita aprender y solo puede comprender haciendo lo que aún no comprende". (1992, p. 85)

La construcción del problema (problem setting) a diferencia de la resolución de problemas de Simon implica una distinción en el abordaje desde lo cognitivo, en cuanto este último refiere y se ajusta a procesos sistemáticos de baja complejidad, cuestión que evidencia la ineficacia de este enfoque. La hipótesis constructivista de Schonn presenta mayor coherencia atiende a la naturaleza dialéctica y compleja de los procesos proyectuales (Burgos, 2010). Esta dualidad conceptual y los problemas que se observan en la enseñanza y aprendizaje conducen a búsquedas y construcciones en el abordaje del problema. Instalados desde esta perspectiva, es preciso reflexionar y revisar el significado vigente de los modos de proyectar y diseñar arquitectura en nuestras universidades. Precisamente, el taller de proyectos es el ámbito de experimentación simulada de estos procesos en su totalidad, entonces, se nos plantea la posibilidad de validar y recuperar el concepto de proyecto de arquitectura como dispositivo central para la enseñanza de la disciplina.

La didáctica del proyecto se reconoce como una didáctica especifica en construcción, esto es abierta, no acabada que aspira a establecer su sistematización. La enseñanza del proyecto es ejercida por arquitectos con formación profesional general que logran su experiencia en lo didáctico-pedagógico de un modo intuitivo y merced a la práctica docente. Sin embargo, las transformaciones culturales y evolución histórica de las instituciones señalan la necesidad de integrar nuevos saberes para revitalizar el compromiso social de la universidad. Considero relevante no solo los modos de hacer, sino cobra importancia la teoría del proyecto y más aún las formas de llevarla a la práctica.

El campo de conocimiento o de los saberes (Sarquis, 2004, p. 29,37) de la didáctica del proyecto se sitúa fundamentalmente en el campo de la práctica, aunque tenga teorías que la sustenten. Pertenece al campo de la praxis, desde el punto de vista de formadores, con la perspectiva de Gilles Ferry, ya que tienen como objeto la acción encaminada a un fin, esto es educativo y para formar un profesional arquitecto requiere de un conocimiento práctico-reflexivo13.

Respecto a lo disciplinar especifico apelamos a las categorías clásicas y la situamos en el campo poietico (Aristóteles) o técnico (Ferry, 1997, p. 75-85), ya que tiene como objeto hacer o producir algo útil, en este caso un proyecto instrumental, como objeto de conocimiento, ya que está en el campo formativo. Por ello se hace necesario un conocimiento técnico, que requiere una reflexión sobre el hacer. (Ver Figura 3) 
Entre los aspectos didácticos-pedagógicos sobresalientes de la arquitectura se caracterizan por que el eje está centrado en el proyecto como dispositivo pedagógico. La formación consiste en un enfoque global, caracterizada por la transversalidad de conocimientos y saberes de diferentes disciplinas que confluyen en el proyecto.

Además hay una jerarquía en la transmisión del saber hacer, con definiciones estrictas en las reglas de progresión. El saber de la arquitectura se extrae del hacer y se alimenta de especulaciones teóricas, utilizando el lenguaje específico del proyecto.

Presenta un núcleo de la tradición simbólico en la transmisión del saber que es el uso de papel y lápiz, que por mucho tiempo fue efectiva, por lo cual no hubo mayores cuestionamientos sobre su adaptación a los cambios sociales y culturales. Por otro lado con el advenimiento del "síndrome de la especificidad" quedan de lado la centralidad y transversalidad del taller de proyectos y pierde fuerza respecto a las áreas teóricas. El imaginario instituido de la experiencia profesional como legitimador en la formación no sólo no es suficiente, sino que en la actualidad el conocimiento del oficio no basta para su enseñanza y hasta es inexistente entre los docentes medios, provocando una fuerte contradicción.

Entre algunos fundamentos de la enseñanza del proyecto hay que señalar:

El taller, atelier o Studio de proyecto. (Schon, 1992; Souto, 2000) está considerado el prototipo de formación profesional. Como dispositivo pedagógico social implica una red de saber y poder, en cuanto a relaciones de significados en el primer caso y de influencias en el segundo, articulando ambas variables.

La reflexión como eje, la reconstrucción critica, (Schon, 1992; Edelstein, 1989, 1995) de las propias prácticas, de los sujetos implicados; del currículo como proceso con intenciones socioculturales pedagógicas, contenidos, estrategias y acciones, como así también reflexión en la acción, en lo especifico proyectual.

La crítica Attoe (1982) es el instrumento en la enseñanza y evaluación del proyecto de arquitectura por antonomasia y es transversal al proceso. Como herramienta presenta problemas. Los imaginarios oscilan entre extrema racionalidad y un exceso de arbitrariedad, y surgen dificultades para realizar una crítica objetiva.

El lenguaje de la crítica presenta conflictos, ya que a veces es provocador, desestructurante, ambiguo, y subjetivo. Se hace necesario incluir las de un orden específico disciplinar objetivable, como la crítica normativa en general, por tipos o la crítica dimensional tal como lo plantea Attoe.

La autonomía en la formación pone en juego diferentes situaciones y posibilidades en la trayectoria con un andamiaje vigotskiano. Así "la formación instruida” y "la formación construida” (Mabardi, 2001; Vigostky, 1978) manifiestan las diferencias de las relaciones en el proceso de construcción del conocimiento y de las asimetrías docente-estudiante que naturalmente deben favorecerse para lograr una mayor autonomía en el desarrollo del estudiante. (Ver Figura 4)

Desde una perspectiva curricular la enseñanza de la arquitectura está basada esencialmente en la enseñanza del proyecto como contenido principal, pues oscila entre el $21 \%$ hasta el $50 \%$ de la carga horaria en relación al Plan de estudios. Al respecto, Monedero (2003) dice, "en todos los países se considera que la enseñanza de la arquitectura debe estar basada en el desarrollo de proyectos y que ésta es una singularidad positiva que debe ser mantenida y desarrollada". (2003, p. 243) (Ver Figura 5) 
En nuestra facultad sobre un total de 4224 horas de dictado en el grado, el porcentaje de carga horaria del área de proyectos es del 39,77 \% sobre el total. La carga horaria asignada al taller es superior a las del resto, es decir, a las otras asignaturas teóricas. Sobre el total, el taller ocupa poco más que una tercera parte; entonces, se observa que las materias teóricas cobran mayor importancia. La tendencia en los últimos tiempos es la tallerización de los espacios de asignaturas teóricas, lo que se podría interpretar como una valoración del dispositivo taller en otras áreas de enseñanza o como una suerte de subvaloración de los contenidos estrictamente teóricos y la necesidad de reforzar la práctica del proyecto.

\subsection{Modelos de enseñanza}

A partir de la identificación de los distintos modelos de enseñanza del proyecto, con sus características más notables, que mostramos sintéticamente: Mimesis, Heurístico, Investigativo (Fernández, 1999); se posibilito la reconstrucción del taller Tradicional de Diseño y el Taller Digital. Para reconocer las principales características se tuvo en cuenta aspectos, como el concepto de arquitectura que tiene de referencia, los sujetos como actores intervinientes, los contenidos que abordan en la estructura curricular, las formas de comunicación que utilizan.

El taller como caja de herramientas (Lagos R., Herrera S., 2006) pone énfasis en la indagación de los medios informáticos, su potencialidad como recurso de comunicación y dispositivo pedagógico. En esta propuesta de talleres experimentales se establece una analogía con los principios de la cultura de la informática: imagen, representación y conectividad y se integran con interés distintas estrategias de enseñanza: seminarios, plataformas virtuales, estructuras formales de notación sistemática, espacios de intercambio transversales con otras carreras, bucles teórico-prácticos. Queda como incógnita en este modelo si se modifica el proceso interno de generación o se usa las técnicas digitales solo como medio representacional y comunicación.

Si el proyecto es núcleo de la enseñanza de la arquitectura, por lo tanto se puede asimilar los Modelos pedagógicos de arquitectura con modelos didácticos o de enseñanza, de modo global. Los estudios conducen a reconocer la clara centralidad y preeminencia del proyecto en los diferentes casos aun cuando presentan particularidades. (Ver Figura 6)

Pautas para una propuesta de modelo didáctico del proyecto:

El proyecto como capital cultural, da lugar a una reproducción de los modus operandi del campo profesional al de la enseñanza, con sus conflictos y contradicciones Pero a la vez las escuelas de arquitectura también son ámbitos de construcción de transformaciones y abren oportunidades de innovaciones en la enseñanza. El taller tradicional se caracteriza en términos generales por prácticas docentes determinadas por el pragmatismo, basadas en la confianza en el saber e idoneidad profesional, el docente como depositario del saber, y con una posición tecnicista, un tanto acrítica. A su vez persiste una subvaloración del saber teórico proyectual como sustento de la práctica. El perfil básicamente profesionalista determina que no haya un profundo sentido reflexivo respecto a las corrientes de moda. Esto se manifiesta en un marcado acople a las tendencias vigentes. Lo que no siempre redunda en tomar las ideas, en términos de sistemas de orden, sino de lo aparente, relacionándose sólo con las cuestiones estilísticas. (Ver Figura 7)

El modelo alternativo propuesto se basa en un Taller Interactivo y Colaborativo entre docentes y alumnos, e inclusivo, que integre el saber teórico en la praxis proyectual, y comprometido con este medio a la vez que 
participe de la cultura global de modo crítico. Al Comparar el modelo instituido tradicional Y el modelo alternativo propuesto, con el rol y las cualidades de los sujetos que intervienen en el proceso, se distingue como sustancial el aprendizaje por competencias versus la reproducción - transmisión de conocimientos.

La articulación teoría-práctica es constitutiva de la formación profesional. La indagación de contenidos y modos de enseñanza; constituye una búsqueda en aportar a un área fundamentalmente práctica, cuya soporte teórico, por un lado forma parte del currículo oculto, en tanto no se explicita, pero también daría cuenta de la debilidad de la dimensión teórica como corpus propio de la disciplina proyectual.

A su vez surge el interrogante: ¿Las estrategias proyectuales14 trabajadas, pueden considerarse, estrategias de enseñanza? En ese sentido recuperamos los conceptos de las didactas Edelstein (1995, p. 68) y Litwin (1997, pp. 13, 14, 46) en cuanto se asimila al concepto de construcciones metodológicas o configuraciones didácticas cuando se prioriza modos particulares disciplinares y su vínculo con las prácticas profesionales.

Por ello infiero que el conjunto de estrategias proyectuales trabajadas se enmarcan dentro del concepto de configuraciones didácticas constituidas por contenidos propios disciplinares, a su vez articuladoras de teoría y práctica, o sea sustentadas por un corpus teóricoconceptual que permiten desplegar modos operativos para la construcción de conocimientos, en este caso el proyecto, por parte de los alumnos.

En el imaginario de los profesionales docentes dedicados a la enseñanza del proyecto permanece la idea -como parte de la cultura instituida- de que sólo los buenos profesionales tienen mayores posibilidades de ejercer mejor la enseñanza. Creemos que la conjunción de experiencia en el saber hacer profesional, la formación teórica disciplinar y la reflexión sobre las propias prácticas son insoslayables en la enseñanza del proyecto.

\section{Una experiencia didáctica de proyecto en la FAU UNT. Electiva Proyecto y Forma}

"No hay alternativa metodológica que pueda omitir la especificidad del contenido (...) solo desde el contenido y una posición interrogativa ante él puede superar la postura instrumentalista en relación al métodos". (Díaz Barriga, 1984)

La propuesta del dictado de la Asignatura electiva Proyecto y Forma apunta a superar la fragmentación entre las áreas teóricas (asignaturas teóricas) y prácticas (taller de proyecto) y crear puentes de vinculación entre lo teórico - conceptual y la praxis proyectual. Por lo tanto se trata de asociar, explorar y desarrollar conocimientos relacionados al área del Taller de Proyecto y la Morfología arquitectónica. De tal modo se reconoce a la forma, como una de las componentes intrínsecas de la arquitectura.

Los cambios y transformaciones culturales en las últimas décadas han marcado también una evolución en el campo de la arquitectura y en su enseñanza, lo que nos interroga acerca de ¿cuáles son los núcleos duros de la disciplina?, ¿qué elementos de la tradición debemos rescatar, revalorizar y re significar? Y, ¿cómo proponer alternativas posibles para enfrentar las dificultades en la enseñanza y mejorar nuestras prácticas?

Tradicionalmente la enseñanza del proyecto se apoyaba sobre dos componentes fundamentales: en el dominio del oficio y la experiencia del profesor en el hacer proyectual; y en la formación y el acopio de los instrumentos teóricos producidos y constatados a través de los tratadistas. Sin embargo, actualmente ambos componentes están en crisis, ya que no todos los docentes tienen ejercicio lo que afecta el oficio profesional, ni 
tampoco disponemos de referentes únicos ni hegemónicos desde el punto de vista teórico. Es por ello que consideramos necesario la reflexión sobre aspectos referidos al tema mencionado. A modo de síntesis de la propuesta curricular de la asignatura el dictado se basa en 3 momentos:

Momento teórico: durante todo el dictado se aspira a plantear cuestiones para discutir y alimentar a los otros dos momentos. (Campos y componentes del proyecto. Concepto y forma. Lenguaje y pensamiento proyectual. Innovación y reproducción etc.)

Momento analítico: a partir del libro llamado La buena vida de Iñaki Abalos, que propone una crítica a 7 casas del siglo XX -y del siglo XXI- de diferentes modos de vida cada una de ellas. Análisis comparativo sus fundamentos filosóficos y su traducción formal. Se considera la propia arquitectura como material de proyecto (Helio Piñon) los propios edificios son fuente de ideas (Einsemnan, 2011, p. 10). La mirada crítica y la lectura de edificios paradigmáticos se consideran fundamentales como material de conocimiento para la actividad proyectual.

Momento proyectual: proponemos proyectar una Unidad de convivencia contemporánea. Todo esto con la idea de realizar una experiencia de aprendizaje, dirigida a la construcción de un proyecto propio (individual y colectivo) a través de un camino crítico.

\subsection{El contenido como eje en la construcción metodológica:}

Estrategias de proyecto Atendiendo que para la construcción de un itinerario didáctico - pedagógico es esencial y no puede ser independiente de los contenidos, se ha trabajado con la reelaboración de lo que llamamos estrategias proyectuales. Estás se derivan de la elaboración de las Cartografía de lógicas convencionales o establecidas y cartografía de lógicas emergentes15, a partir de las cuales se ha derivado e inferido el menú de estrategias que aquí se presentan. Por otro lado están los temas desarrollados que constituyen otro nivel de contenidos específicos. (En el caso que se muestra como ejemplo se priorizo el tema Vivienda de Emergencia ambiental y productiva).

Un aporte sustantivo como contenido teórico-práctico en esta experiencia didáctica está en el abanico de estrategias proyectuales identificadas (Ben Altabef, 2010, p. 129), usadas en el proyecto arquitectónico. Se propone este mapa, no cerrado ni acabado, de estrategias proyectuales, se debe señalar que las taxonomías propuestas, tanto las convencionales como emergentes, no se constituyen en clasificaciones homogéneas ni jerárquicas. Sintéticamente se señalan algunos aspectos:

1. EI PARTIDO es una de las modalidades más arraigadas en los ámbitos profesionales y de la enseñanza. Constituye la estrategia de carácter holístico por excelencia en el proyecto mediante la cual es posible organizar una unidad totalizadora, a través de un esquema sintético y cumple la función de mediador entre la idea y la resultante formal. Si la arquitectura de partido constituye una opción cerrada, lineal, fuerte en lo formal y funcional, surge el interrogante: ¿es posible a través de un esquema simple dar cuenta de la complejidad que el problema de la arquitectura representa actualmente? Pueden identificarse diferencias entre el Partido del Academicismo -uso de tipos-; en la Modernidad -con el programa como núcleo identitario- y en nuestra contemporaneidad; de un modo menos sintético. Merced a realizar estas distinciones es posible reivindicar esta modalidad. 
2. El uso del TIPO y de las TIPOLOGÍAS abre el ya polémico debate del proyecto innovador frente al reproductor. Son significativas la permanencia y la transformación de los tipos, por lo cual se consideran pilar epistemológico disciplinar. Nos proponemos resinificarla como instrumento, tal como lo hicieron Corbu, Mies o Alvar Aalto, que demostraron la validez universal del tipo en el proyecto, porque aún a ellos, acusados de haber hecho tabula rasa, se los puede analizar en clave tipológica si se la entiende como un instrumento flexible en el proyecto, como señala (Aris, 1993, 103). Tal uso dio lugar a un lenguaje con códigos nuevos y confirman el potencial que poseen.

Tanto el partido como los tipos se consideran estrategias factibles de ser reinterpretadas y re significadas y así modificar su alcance en los procesos de proyecto.

\section{LAS ANALOGÍAS Y METÁFORAS CONCEPTUALES Y FORMALES son consideradas como uno de los} instrumentos más ricos y creativos. Así los modelos analógicos han tenido probado uso ante problemas complejos y desconocidos. Estas estrategias se usan con mayor y menor nivel de iconicidad, en tanto responden con procesos más o menos figurativos o abstractos. Las relaciones de semejanzas sirven para la interpretación de problemas y para dar lugar a la generación formal y se nutre de distintas disciplinas.

4. DIAGRAMAS E IDEOGRAMAS, con sus múltiples acepciones e interpretaciones. Los diagramas son instrumentos de análisis y reconocimiento y operan como una "máquina" de acción generativa y productiva (Gausa, et al. 2000, p. 621). Hay una doble lectura del diagrama dado el juego dialéctico entre lo abstracto y lo concreto que proponen la mayoría de las veces formas de organización. Tradicionalmente se asociaba la idea de diagrama con la del esquema geométrico. Se los utilizó como modelos de análisis de estructuras sociales y organigramas funcionales en los 60 y 70 . Luego aparece el diagrama como medio de explicación de problemas y de realidades a veces ininteligibles y se toman modelos de otras disciplinas -como las ciencias y las artespara describir complejidades del mundo.

5. Una fuente primaria generadora de conceptos es la exploración de la MATERIA como medio proyectual. La indagación rigurosa como punto de partida para extraer conceptos es un modo poco investigado en nuestro ámbito. La valoración de lo sensorial nos permite identificar las materias y materiales, tanto densos como sutiles (Naselli, 2004). Henrie Focillon, señala, que la forma sólo es una abstracción mientras no viva en la materia. Las materias poseen cierta vocación formal en su condición natural, primaria, y en estado alterado y manipulado artificialmente como material. La experimentación, el descubrimiento de cualidades, permite crear puentes entre la conceptualización y la formalización de una idea.

6. Consideramos de interés las PAUTAS como estrategia de definición del qué proyectar, esto es en el territorio de la definición del programa cualitativo. Tienen como encuadre a la teoría de sistemas, en una concepción totalizadora de Alexander, con una búsqueda analítica y racional. Las pautas usan un lenguaje abstractoconceptual que da lugar a un embrión formal. Con otro enfoque, Federico Soriano (2004, p. 8) formula patrones de pensamientos, como "pautas, patrones, estructuras, disposiciones (...) formas que asocian idénticos sistemas de orden o de geometrías desde fenómenos y disciplinas distintas"

7. El punto de partida puede ser también un FRAGMENTO (Trabucco, 1999, p. 61) de tipo conceptual o formal. En la generación con los fragmentos, los nexos y el hilo conductor son temas importantes por lo que aparecen 
diferentes criterios de articulación de las partes y de la concepción de totalidad. Manuel Gausa afirma que el collage es un método de representación, de producción y de proyectación.

8. El programa es, núcleo constante, determinante e ineludible en la arquitectura. La dimensión funcional, tanto utilitaria como estética, le es inherente. Los habituales programas de necesidades representan pautas funcionales relativamente precisas y fijas. Flora Manteola señala:

(...) el programa en general ha venido siempre como una enunciación de locales, eso genera una situación muy paralizante. Cuando aparece la lista de locales están dando como los sustantivos de una sintaxis, faltan los verbos, (...) estos son esenciales porque la arquitectura no son locales, sino acontecimientos, son cosas que van sucediendo desde el espacio y en el tiempo y (...). (Manteola, 2004, p. 57)

Las transformaciones de patrones y conductas muestran la necesidad de trabajar con PROGRAMAS DE USOS como sistemas más flexibles que atienden a la complejidad de los diferentes modos del habitar, de acuerdo a diferentes contextos.

9. LOS PROCESOS DE HIBRIDACIÓN tratan de la superposición de informaciones conceptuales y gráficas. La construcción de estas "intersecciones" o puntos de contacto de distinto nivel favorece la interpretación de un modo simultáneo y paralelo de varios problemas. La hibridación puede entenderse como la mezcla y la conjunción de información (Arroyo, 2001), común en el proceso proyectual por los múltiples problemas que se abordan.

10. Los PROCESOS I-LOGICOS plantean otras vías de entrada a partir de la manipulación de la forma concreta como punto de partida del proceso proyectual. Son caminos no ortodoxos, no convencionales y dan lugar a otras lógicas. Se entiende como i-lógico un modo no demasiado sensato, ni racional. Según Naselli “(...) La idea aparece como un proceso más mutable, al final, como culminación de un camino exploratorio y entendiendo al proyecto como una oscilación" $(2002,112)$, hecho que la arquitectura de partido congela. Las vías de la i-lógica nos permiten trabajar a partir de la valoración de la intuición y los mecanismos de lo inconsciente. A riesgo de plantear una dicotomía se puede ver, en un extremo, la arquitectura de tipos o de partido -objetual-y acabada y, en el otro, la arquitectura de proceso que incluye lo subjetivo y poético.

Aun así, una mirada crítica impone limitar su uso indiscriminado, ya que si no se considera el contexto de implementación, puede resultar banal y frívolo: la seducción de lo visual deja de lado el carácter multidimensional de lo arquitectónico y produce una deshumanización.

\subsection{Proceso y resultados}

Tomando el concepto de transposición didáctica (Chevallard, 2000), se plantea una re conceptualización de la construcción teórica sobre estrategias proyectuales, como conocimiento a adaptar y transformar, que se constituyó en el andamiaje teórico - práctico, de las experiencias didácticas.

La ejercitación que se expone; en el Momento proyectual, plantea como problemática de proyecto desarrollar una Unidad de convivencia contemporánea, cuya definición programática (tipo de usuarios y tipo de U.C.) y de localización estará a cargo de cada estudiante o grupo que estará en relación a lo anteriormente dispuesto. Asimismo se plantea la explicitación y selección de estrategia/s para abordar el proyecto. 
Se ha tenido como propósitos de la experiencia proyectual, modificar las secuencias habituales del proceso de proyecto para evitar las configuraciones convencionales y prestablecidas. Incentivar a racionalizar el uso de diferentes/ otros procedimientos que favorezcan otros en las experiencias proyectuales. Favorecer procesos e itinerarios creativos no convencionales como punto de partida y llegada en propuestas proyectuales.

Los aspectos o variables de proyecto se explicitan en una matriz que plantea una selección y uso no necesariamente secuencial para el abordaje de la problemática que se propone. Se la ha volcado en esta matriz a modo de una caja de Zwicy que permite diferentes combinatorias, caminos alternativos y así posibilidades de trayectorias proyectuales diferenciadas. Se propone que las variables se combinen, no necesariamente de modo secuencial para la construcción programática de la propuesta proyectual:

Se Identifica para su selección distintos tipos de usuario/ familia destinataria de la propuesta; Identificación de Contexto y sitio de ubicación. Condicionantes y determinantes del sitio (Ideas de límites y relaciones: interfaces: interior - exterior; público - privado: esclusas y transiciones); ideas específicas en la materialización: tectónica (ligereza), estereotómica (solidez), opacidad, transformación, transparencia, mutabilidad, inmutabilidad, interioridad, exterioridad, horizontalidad, verticalidad, etc.); Explicitación de la selección de estrategia/procedimiento seleccionado para el abordaje del proyecto (según lo tratado en clase). Fundamentación. Referencias conceptuales y ejemplos pertinentes.

A continuación un ejemplo de trayectorias elegidas a partir del Mapa de variables para las Propuestas proyectuales. (Ver Algunos de los resultados de Propuesta proyectuales16, Figura 8)

\section{Reflexiones y apertura}

Con el fenómeno de la globalización y el quiebre cultural a partir de la revolución informática, aparecen fisuras y contradicciones significativas. Las transformaciones en el campo de la informática constituyen un punto de inflexión en el curso de la historia. Se ha producido ya una ruptura cultural en los sistemas de comunicación. La ilusión de la globalización como posibilidad de interacciones y comunicación confronta con una realidad tensada por asimetrías y exclusión de distinto orden. En el caso de la arquitectura, el escenario no es claro y, se visualiza una coexistencia de diferentes paradigmas e ideologías. Si bien se han producido innegables transformaciones, creemos que la ruptura en términos de Khun, en cuanto al pensamiento disciplinar en su conjunto, aun es débil y borrosa. En esta transición de paradigmas pleno de ismos vienen apareciendo dentro de la cultura disciplinar corrientes diversas y múltiples, como el posmodernismo, decontructivismo, neorracionalismo, parametricismo, ecologismo, bioclimatismo, que abren un debate continuo y dinámico.

La consideración de Battisti de contemplar a la tipología, la técnica y la morfología como núcleos disciplinares centrales para una ideología de la arquitectura, siguen teniendo valor en el siglo XXI. Aun cuando haya que sumar otros recursos de proyecto que contemplan los avances informáticos y tecnológicos. Reivindicamos la vigencia de la tipología, como medio específico de conocimiento y de proyecto lejos de considerarla un instrumento estéril y perimido ya que su implementación es sostenida porque aparece presente aun en la llamada arquitectura digital.

Los contenidos teóricos disciplinares hay que considerarlos de naturaleza ideológico plausibles de transformación en vías de la construcción de un corpus objetivo y racional. Así los conocimientos teóricos acerca 
del proyecto y de la morfología deben estar en continua revisión dinámica, sistemática y critica. Se trata de constatar su aplicabilidad en relación a la realidad en que intervenimos.

Los grandes avances tecnológicos específicos en el campo de la construcción posibilitan formas en consonancia con esta sociedad de contradicciones del espectáculo. Sin embargo, si uno debiera especificar cambios radicales, tales como la planta libre del proyecto moderno, que constituyó un aporte verdaderamente revolucionario al pensamiento disciplinar, se nos plantearían dudas.

El análisis crítico y eficaz de arquitectura es como lo señalan tanto Helio Piñón y Peter Einsenman, material de proyecto y fuente de ideas para la arquitectura. Cultivar el ojo crí- tico y bucear en lo profundo y no solo en lo aparente de la arquitectura, poder distinguir lo estructural de lo superficial es central en lo proyectual. Puede ser paradójico que en la era de la información nuestros estudiantes tengan una cultura arquitectónica pobre.

Hay transformaciones que pueden confundirnos pero creemos que existe una debilidad en innovaciones consistentes. Asimismo, la falta de perspectiva histórica nos impide la valoración de la arquitectura contemporánea, ya que mucha de ella es de dudosa supervivencia a pesar de su espectacular factura y alto impacto visual. Consideramos que aún asistimos a un tiempo de transición, en el cual se revaloriza el proyecto moderno de modo silencioso. Se abre un nuevo panorama que tiende a un proceso de hibridación cultural relacionado con una crisis en la identidad, en su definición y legitimación de los discursos. La idea de identidad en lo disciplinar de nuestra contemporaneidad, no es pura ni fija o clausurada, sino un concepto móvil que podemos asociar a una identidad reflexiva o hibrida, que tiene más que ver con una identidad que se construye, no "fraguada" al decir de Zigmunt Baumann (2007, p. 69). Por lo tanto se presenta a través de una coexistencia de lenguajes que muestra esa diversidad, heterogeneidad que en general rescata los valores del contexto con distintas modalidades. En esta crisis de certezas prevalece en el pensamiento una actitud tolerante y un pluralismo crítico hacia nuevos y heterogéneos principios que parece ya aceptada en la sociedad.

Considerar la potencialidad transformadora de la arquitectura y el proyecto, significa revisar sus prácticas dejando de lado la enorme subjetividad en las elecciones en su ejercicio en favor de prácticas más objetivas y racionales adecuadas a la realidad urbana donde intervenimos.

A modo de reflexiones finales, en el ámbito de la enseñanza, quisiera señalar que se pueden observar todavía desajustes relativos entre el saber docente -inmigrante digital- y el saber de los estudiantes -nativo digital-; en relación con los medios digitales, por lo tanto, debieran promoverse sistemas de colaboración de formación, en cuanto el docente debe ser también sujeto de aprendizaje.

Esto se vincula a una mirada tecnicista o cultural - social de las técnicas digitales e informáticas. Se deriva de la concepción que tengamos, por un lado, de la arquitectura (como hecho o fenómeno cultural) y, por otro, del concepto de educación, en cuanto a la relevancia del estudiante como protagonista que construye los conocimientos - proyecto- y del docente que guía y cómo guía, más que como único depositario del saber. La utilización de la informática y las técnicas digitales, implica no sólo considerarlas como medio de representación sino para la generación de la forma arquitectónica, sino también como medio de comunicación y articulación.

En términos generales, estamos en condiciones de afirmar que conocer la tradición es necesario para poder innovar. Conocer la ley es ineludible, si se pretende en algún momento transgredir esos límites para innovar. La 
enseñanza debiera incluir modalidades convencionales así como también otras emergentes, para poder confrontarlas o usarlas de modo complementario en el hacer. Por ello es que nuestra propuesta es de carácter inclusivo, con cierto grado de ambigüedad. Sin embargo, lo que queremos mostrar es que pareciera que el equilibrio estaría tensado, por un lado, en el conocimiento y uso profundo de la tradición, y, por otro, en la interacción con una intención de experimentación y búsqueda constante.

\section{Notas}

1. Tal como lo plantea Roberto Doberti (2008), el conocimiento en occidente presenta tres categorías convencionales: las ciencias, las artes y la tecnología. El rasgo básico de la Ciencia es el conocimiento fundado en la razón, el Arte como conocimiento a través de la expresión sensible del ser humano, mientras que la Tecnología implica procedimientos para modificar el medio natural (o ciencia aplicada que tiene entidad propia). Hay quienes, como Doberti, abogan por una "Cuarta Posición". Se considera que las disciplinas proyectuales no encuadran en esas categorías de modo estricto constituyen una cuarta categoría. Lo cierto es que específicamente la arquitectura, no es Arte ni Ciencia ni Tecnología, su rasgo básico es la prefiguración o planificación del hábitat y entorno humano. Así, "el Proyecto (considerado en todas sus modalidades) tiene el mismo rango o status, el mismo valor identificatorio que tienen la Ciencia, el Arte y la Tecnología. Esto quiere decir que no puede subsumirse en ninguna de las otras áreas, ni es una mezcla o combinación de ellas" (p. 214) como habitualmente se dice. Esta tesis puede ser muy arriesgada y temeraria, pero considerarla nos posicionaría en otro lugar de poder, tanto en el plano político como hacia el interior de la disciplina.

Ya en 1979 Herbert Simon, en Las ciencias de lo artificial, plantea la identificación de las actividades relacionadas con el diseño como la música, ingeniería, arquitectura, cuyos procesos de producción tienen modalidades análogas como áreas del conocimiento diferenciados del arte, ciencia y tecnología.

2. Fragmento de: Ben Altabef, Clara (2010) El pasaje del concepto a la forma en el proyecto de arquitectura: Un desafío didáctico (Tesis de Doctorado) Inédito. FAU. UNT. Tucumán. pp. 81-85.

3. Un modo de comprensión de la obra de arquitectura es partir del planteo de la triada vitruviana, lo que implica entenderla como una tríada de venustas, firmitas y utilitas -belleza, solidez y utilidad, o sea forma, técnica y función- inserta en una estructura de contexto determinado y como una totalidad. La hipótesis de Vitrubio presenta al proyecto y a la arquitectura misma como una ligazón de estas dimensiones. ¿Cuál es la re significación de esta definición que podemos elaborar en nuestra contemporaneidad? El espíritu del tiempo modifica el sentido de los términos. La belleza -venustas-, que antes implicaba una determinación formal a través de fórmulas matemáticas conocidas, se transforma en una pluralidad de interpretaciones estéticas en las que rigen otros conceptos, como la ingravidez y la indeterminación de la forma-espacio. La firmitas, solidez y durabilidad física para la antigüedad, adquiere otra orientación, más dirigida a lo sustentable, a lo sostenible. Para Vitrubio la arquitectura debía sobrevivir, no ser sustentable en el sentido contemporáneo del término. La utilidad -utilitas- hoy está marcada, en ciertos ámbitos, por lo efímero, lo intercambiable, producto de las transformaciones y cambios acelerados.

4. Se entiende cómo "ideología, en el sentido marxista; en donde se acepta como manifestación de una falsa conciencia que pretende definir la superestructura, pensamiento -religioso, jurídico, artístico- operando al 
servicio de los intereses de la clase dominante" (p. 17). Se entienden casi como opuestos, el concepto de ciencia y el de ideología.

En el pensamiento materialista dialéctico, la estructura es la base económica y la superestructura está constituida por las manifestaciones o formas ideológicas: jurídicas, políticas, y religiosas, artísticas y filosóficas. La verificación de su validez depende de la confrontación con el mundo real. Si no sirven para adquirir conocimientos son simplemente "ideología", es decir falsa conciencia o conocimientos deformados de la realidad. La relación entre estructura y superestructura amerita un análisis histórico - económico a partir de los cuales se deducen los aspectos de la superestructura (p. 231-214). Hay que señalar que no se trata de un análisis mecanicista y presenta muchos problemas, para crear un pensamiento que se llama científico u objetivo.

5. Algunas vertientes, han presentado concepciones racionalistas y cientificistas, por ejemplo el Circulo de Viena, que sostenían que la técnica es vía de progreso social, lo cual abona una posición tecnocrática donde las cuestiones referidas a la ciencia y a la técnica se consideran independientes de la cultura.

6. Emilio Battisti (1975), señala al respecto:

Una segunda contradicción se origina directamente del papel social del intelectual en una sociedad capitalista: consiste en el hecho de que el tipo de representación que los arquitectos pueden elaborar sobre la base material a la que hacen referencia es necesariamente la suministrada por la clase dominante y son solo estas ideas las que pueden ser traducidas para constituir el momento de la práctica empírica de la arquitectura. Esto supone que los arquitectos, al parecer como intelectuales, no pueden hacer otra cosa que formar parte funcional de la estructura de poder, actuando como ideólogos de la clase dominante. (p. 224)

7. Jorge Sarquis analiza y desarrolla de modo exhaustivo la evolución de la idea de proyecto; para ello estudia las acepciones, desde diferentes autores y disciplinas, como así también las distintas teorías sobre el proyecto. Consideramos relevante el racconto erudito que allí se realiza y se recomienda consultar su obra para profundizar. Analiza en profundidad los conceptos de composición, proyecto y diseño desde la antigüedad clásica, renacimiento, modernidad hasta nuestros días, abrevando de distintos autores.

8. Fragmento de Conferencia dictada en el X Congreso Nacional de Expresión Gráfica en Ingeniería, Arquitectura y Carreras Afines. Octubre 2013 Tucumán. Argentina.

9. Se señalan un fragmento de hipótesis Ben Altabef, Clara (2010) El pasaje del concepto a la forma en el proyecto de arquitectura: Un desafío didáctico (Tesis de Doctorado) Inédito. FAU. UNT. Tucumán. (pp.21-29)

10. La noción de forma presenta un carácter polisémico, ya que puede ser tratada desde diversos puntos de vista. Montaner (2003) respecto al sentido del concepto de forma afirma:

...Posee una enorme ambigüedad y una gran cantidad de significados (...). La idea de forma (...) nada tiene que ver con la forma exterior o apariencia visual, como contorno silueta, ni mucho menos con la forma como género o estilo artístico. La concepción que se adopta como seminal es la de forma entendida como estructura esencial e interna, como construcción del espacio y de la materia. Desde esta concepción forma y contenido tienden a coincidir. (p. 6) 
11. "Estrategias de enseñanza como el conjunto de operaciones que realiza el docente para organizar factores y actividades que intervienen en el proceso de enseñanza y aprendizaje de un determinado contenido" (Furlan, 1979).

12. Desde lo disciplinar Gastón Breyer (2003) plantea que existen formas claves de enseñar y aprender. Una de ellas, la enseñanza por resonancia, refiere a las actividades que se aprenden haciendo, como los oficios, la danza, el proyectar arquitectura, donde los docentes guían y estimulan a los estudiantes para que desarrollen sus capacidades.

13. Gilles Ferry señala "Schon habla de los prácticos reflexivos, es decir el practico que tiene la capacidad de pensar, reflexionar sobre su acción en todos sus aspectos no solo los técnicos sino también en los ideológicos...." (1997, p. 79)

14. Se desarrollan un extracto en el próximo punto (Ben Altabef, 2010)

15. Al plantear esta búsqueda me dispuse detectar los distintos modos de prácticas profesionales que conducen a la antesala de lo pedagógico. Con la hipótesis referida al estrecho vínculo que existe en los pares: producción del proyecto-ámbito profesional y reproducción del proyecto-ámbito de enseñanza, a partir de los modelos de enseñanza.

Entendemos las lógicas proyectuales como los modos de concebir, procesos de generación arquitectónicos articulados, que están sustentados por la práctica, y pueden dar lugar a concepciones teóricas a partir de la conceptualización de Roberto Fernández.

En primer lugar se desarrollo una cartografía, llamada convencional o aceptada, pues se define a través de aspectos consensuados disciplinalmente. Es una perspectiva teñida de un enfoque historicista en tanto predominan taxonomías organizadas y jerárquicas. Este mapa plantea prácticas de arquitectura a través de la lectura de los modos proyectuales y de generación formal. Importa señalar que no todas las clasificaciones tienen el mismo enfoque; algunas son más globales, como las de G. Broadbent y R. Fernández, y otras más focalizadas, como las de F. Purini o A. Corona Martínez.

Se ha ubicado en forma paralela, de un modo comparativo, los distintos modos aquí explicitados; dando cuenta de prácticas habituales. Lo relevante es marcar que, en distintas taxonomías, se deducen estrategias que aparecen de modo reiterado, a veces directamente y otras no.

En la segunda cartografía de lógicas que llamé emergentes, se identifica algunas lecturas de las vanguardias. Aquí se observa disparidad y fragmentación en las categorías de análisis que incluyen diferentes campos culturales. Esta proviene de la interpretación de escritos contemporáneos, que evidencian la ausencia de modelos y de discursos homogéneos, vinculados con la arquitectura, las ciencias, el arte y la filosofía. Se seleccionaron tres vertientes relevantes, porque identifican tendencias en las prácticas disciplinares recientes. Se trata de tres intelectuales que ejercen la profesión, la crítica y la academia: Ignasi de Solá Morales, Federico Soriano, y Alejandro Zaera Polo. Este último propone una lectura del presente de la arquitectura, con una original perspectiva. Señala, entre otras cosas, que "vivimos en un mundo que nos parece fragmentario, un mundo hecho de mundos (...). Ya no es suficiente estudiar a Mies, Corbu o Palladio para encontrar la verdad, y 
ahora que ya no existe un mundo único, una única verdad, las revistas de arquitectura son instrumentos muy poderosos para la práctica contemporánea, más que los tratados".

Einsenman señala que crítica debe realizar un enfoque provisional, detectando diferentes situaciones para trazar el estado de la arquitectura actual; no se puede plantear un "esquema arborescente, entendiéndolas como unas ramas de un árbol (...). La arquitectura no es un árbol, es tan solo un acontecimiento resultante de un cruce de fuerzas del lugar (...)" Ignasi de Sola Morales: Diferencias. Topografía de la arquitectura contemporánea, Barcelona, Edit. Gustavo Gili, 2003, p. 8.

Si se hace un análisis comparativo de los distintos modos aquí explicitados, ("Modos de trabajo" de Soriano y "Cartografías contemporáneas" de Zaera), se puede identificar el uso de diversas estrategias proyectuales. En algunos casos esta deducción es casi directa y explícita porque tales estrategias resultan comunes en ambos enfoques. Zaera Polo, Alejandro: “Un Mundo lleno de agujeros”, El Croquis 88/ 89, Madrid, El Croquis Editorial, 1998, p. 308.

Se debe señalar que las taxonomías propuestas, tanto las convencionales como las vanguardistas, no se constituyen en clasificaciones homogéneas ni jerárquicas.

16. Participación en el Concurso "ARQUISUR 2013 PREMIO INVESTIGACIÓN - Cat. 1 del XXXII ENCUENTRO y XVII CONGRESO ARQUISUR: HABITAR LA CIUDAD, TIEMPO Y ESPACIO. Facultad de arquitectura, urbanismo y diseño. UNC. Set.2013. $3^{\circ}$ mención en dos categorías investigación (Estudiantes y Tesis inédita).

Título: "Didáctica proyectual: un problema, tres soluciones. Caso: unidades de convivencia para emergencia ambiental". Equipo docente: Dra. Arq. C. Ben Altabef, Arq. S. Salvatierra, Arq L. Pedicone y los estudiantes: E. Fernández Lafuente, Y. Chiambretto, L. Gramajo, G. Rojas. El trabajo se desprende del Proyecto de investigación CIUNT 26B 407: "Didáctica proyectual. Morfología del espacio social y contexto" (FAU.UNT. 20082013) y en el marco del dictado de la Asignatura Electiva "Proyecto y Forma 2012-2013".

Abstract: With the phenomenon of globalization and the cultural break from the informatics revolution, there are significant fissures and contradictions. Transformations in the field of informatics are a turning point in the course of history. There has already been a cultural breakdown in communication systems. The illusion of globalization as a possibility of interactions and communication confronts a reality tensed by asymmetries and exclusion of different order. In the case of architecture, the scenario is not clear and a coexistence of different paradigms and ideologies is visualized. While there have been undeniable transformations, we believe that the rupture in terms of Khun, in terms of disciplinary thinking as a whole, is still weak and blurred. In this context, the theoretical disciplinary contents must be considered of an ideological nature plausible of transformation in the way of the construction of an objective and rational corpus. Thus the theoretical knowledge about the project and the morphology must be in continuous dynamic, systematic and critical review. It is to verify its applicability in relation to the reality in which we intervene.

Key words: architecture teaching - paradigm - ideology - theory - practice

Resumo: Com a globalização e o quebre cultural produzido pela revolução informática, aparecem fissuras e contradições significativas. As transformações no campo da informática constituem um ponto de inflexão no 
curso da história. Já se produz uma ruptura cultural nos sistemas de informação. A ilusão da globalização como possibilidade de interações e comunicação confronta com uma realidade esticada por assimetrias e exclusão de diferente ordem. No caso da arquitetura, o cenário não é claro e se vê a coexistência de diferentes paradigmas e ideologias. Embora se produziram inegáveis transformações, a ruptura em termos de Khun, em relação ao pensamento disciplinar no seu conjunto, ainda é débil e impreciso. Neste contexto, os conteúdos teóricos disciplinares devem se considerar de natureza ideológica possíveis de transformação para a construção de um corpus objetivo e racional. Assim, os conhecimentos teóricos sobre o projeto e a morfologia devem estar em permanente revisão dinâmica, sistemática e crítica. Trata-se de constatar sua aplicabilidade em relação á realidade.

Palavras chave: ensino da arquitetura - paradigma - ideologia - teoria - prática.

Intenciones para una didáctica proyectual. Caso: asignatura Proyecto y Forma en la FAU-UNT fue publicado de la página 101 a página133 en Cuadernos del Centro de Estudios de Diseño y Comunicación № 67 